\title{
Produção de conídios em substrato sólido e colonização superficial por Trichoderma harzianum
}

\author{
Paulo Henrique Pereira Costa Muniz ${ }^{1}$, Gustavo Henrique Silva Peixoto ${ }^{1}$, Maysa Pereira \\ Martins Teixeira ${ }^{1}$, Sueli Corrêa Marques de Mello², Daniel Diego Costa Carvalho ${ }^{1}$ \\ ${ }^{1}$ Universidade Estadual de Goiás, Campus de Ipameri, Ipameri, Goiás, Brasil. E-mail: paulohenrique.muniz1@gmail.com, \\ gugspeixoto@gmail.com, maysapmteixeira@outlook.com, daniel.carvalho@ueg.br \\ ${ }^{2}$ Embrapa Recursos Genéticos e Biotecnologia, Brasília, Brasil. E-mail: sueli.mello@embrapa.br
}

Recebido: 17/04/2018; Aceito: 17/08/2018.

\section{RESUMO}

Alguns fungos apresentam difícil esporulação em meios artificiais. Neste contexto, o processo de produção massal de conídios de Trichoderma sp., para o emprego em biocontrole mais utilizado, se baseia na multiplicação por meio da fermentação em substrato sólido. O objetivo deste trabalho foi estudar a produção de conídios de cinco isolados de $T$. harzianum em substrato sólido e a capacidade destes para colonização superficial de meio de cultura rico em sacarose. Para tanto, os isolados foram submetidos à produção de conídios em substrato sólido (arroz parboilizado umedecido e autoclavado) a $25{ }^{\circ} \mathrm{C}$ e a fotoperíodo de $12 \mathrm{~h}$ por sete dias. Em seguida, os conídios foram inoculados em quadrados $(1,5 \times 1,5 \mathrm{~cm})$ de batata dextrose ágar-sacarose (BDA-S) para se estimar o percentual de colonização dos quadrados às $12,24,36$ e 48 horas após a inoculação a $25^{\circ} \mathrm{C}$ e fotoperíodo de 12 h. O percentual de colonização foi integralizado como AACCM (área abaixo da curva de crescimento micelial). Os isolados de T. harzianum apresentaram capacidade de colonização superficial em BDA-S acima de 50\%, com $48 \mathrm{~h}$ após a inoculação. Além disso, apresentaram resultados promissores para a produção massal de inóculo $(0,5$ a $2,6 \times 10^{8}$ conídios $\mathrm{mL}^{-1}$ ).

Palavras-chave: controle biológico, esporulação, viabilidade.

\section{Production of conidia on solid substrate and superficial colonization by Trichoderma harzianum}

\begin{abstract}
Some fungi have a difficult sporulation in artificial media. In this context, the mass production process of conidia of Trichoderma sp., for the most used use in biocontrol, is based on the multiplication by means of the fermentation in solid substrate. The objective of this work was to study the conidia production of five isolates of T. harzianum on solid substrates and their capacity for surface colonization of sucrose-rich culture media. For this, the isolates were submitted to conidia production on solid substrates (parboiled and moistened autoclaved rice) at $25^{\circ} \mathrm{C}$ and $12 \mathrm{~h}$ photoperiod for seven days. Then, the conidia were inoculated into squares plugs $(1.5 \mathrm{x} 1.5 \mathrm{~cm})$ of potato dextrose agar-sucrose (PDA-S) to estimate the colonization percentage of the squares at 12, 24, 36 and 48 hours after inoculation at $25{ }^{\circ} \mathrm{C}$ and $12 \mathrm{~h}$ photoperiod. The percentage of colonization was integrated as ABMGC (area below the mycelial growth curve). The T. harzianum isolates showed surface colonization capacity on PDA$\mathrm{S}$ above $50 \%$, with $48 \mathrm{~h}$ after inoculation. In addition, they presented promising results for the mass production of inoculum $\left(0.5\right.$ to $2.6 \times 10^{8}$ conidia $\left.\mathrm{mL}^{-1}\right)$.
\end{abstract}

Keywords: biological control, sporulation, viability. 


\section{Introdução}

Alguns fungos apresentam dificuldade em produzir esporo em meios artificiais. Para exemplificar, pode-se citar a produção de conídios por alguns isolados de Alternaria alternata, que requer técnicas especiais, a exemplo da submissão do micélio a estresse físico na forma de indução de lesões nas colônias ou choque frio destas (Carvalho et al., 2008). Outro exemplo compreende relatos sobre a utilização de meios sintéticos convencionais, como glicose, celulose, amido solúvel e melaço para produção de conídios de Trichoderma sp. (Brand et al., 2010). No entanto, o custo destas matérias-primas mencionadas para a produção comercial de Trichoderma sp. é uma das principais limitações que convergem para um uso restrito deste agente de controle biológico (Cavalcante et al., 2008). Neste sentido, pode-se citar a sacarose como componente de meios de cultura, a qual possui menor custo em comparação com a dextrose.

Microrganismos antagonistas devem ser facilmente cultivados em meios de cultura disponíveis, com algumas exigências relativas às suas necessidades nutricionais, de modo que grande parte do inóculo possa ser facilmente obtida (Fortes et al., 2007; Gao et al., 2007). Portanto, para várias espécies e isolados de fungos, métodos simples e menos dispendiosos para fazê-lo são muito bem-vindos (Alizadeh et al., 2011).

O processo de produção de espécies de Trichoderma em substrato sólido empregado no Brasil, na verdade, não é automatizado e apresenta deficiência em relação a estudos com o objetivo de maximizar a produção e a padronização de conídios. Técnicas inovadoras e conhecimentos sobre as necessidades fisiológicas do gênero Trichoderma devem estar disponíveis a fim de proporcionar uma evolução do setor de controle biológico (Machado et al., 2012).

Ampliações na produção de produtos biológicos devem ser cuidadosamente programadas nas indústrias e avaliadas para que aumentos na produção de Trichoderma para uso comercial não gerem problemas relacionados com a qualidade final das formulações, dentre os quais a viabilidade dos conídios produzidos (Lopes, 2009).

Após o processo de produção em laboratório, os esporos dos microrganismos antagônicos precisam germinar e desenvolver com rapidez em condições de campo (Wood e Tveit, 1955). Em outras palavras, eles precisam apresentar viabilidade e capacidade de colonização de uma superfície (Negri et al., 2010); além disso, dependem das condições ambientais, do alvo e do processo de aplicação do produto. Desde que o processo de produção em laboratório possua um papel importante na sobrevivência e viabilidade de conídios produzidos (Mukherjee et al., 2003), a avaliação da capacidade para a colonização de uma superfície sólida compreende um passo necessário para um programa de controle biológico (Thangavelu et al., 2004; Louzada et al., 2016).

Neste contexto, no processo de produção massal de propágulos de Trichoderma para emprego em biocontrole, são necessários substratos que proporcionem rápida multiplicação. Atualmente, o processo de produção se baseia na multiplicação por meio da fermentação em substrato sólido que, segundo Lopes (2009), consiste no uso de cereais ou grãos précozidos como substrato, principalmente arroz. $\mathrm{Na}$ literatura, também há relatos do uso de milheto, sorgo, trigo e fubá de milho como substrato (Singh et al., 2007), em que o fungo coloniza esses substratos e produz esporos aéreos. O cultivo de fungos em larga escala, que se baseia em substratos sólidos, oferece a vantagem de ser prontamente biodegradável, imitador das condições ambientais naturais de alguns microrganismos (Spadaro e Gullino, 2005; Fortes et al., 2007). Além disso, os conídios produzidos sob este processo apresentam maior tolerância a estresses abióticos (Bhargav et al., 2008).

Deste modo, a fermentação em substrato sólido apresenta-se como um método eficaz na produção do inóculo. O objetivo deste trabalho foi avaliar a produção de conídios de $T$. harzianum em substrato sólido e a capacidade destes para colonização superficial de meio de cultura rico em sacarose.

\section{Material e Métodos \\ Isolados de Trichoderma harzianum}

Os cinco isolados (CEN287, CEN288, CEN289, CEN290 e CEN316) de T. harzianum utilizados neste trabalho pertencem à Coleção de Fungos para Controle Biológico de Fitopatógenos da Embrapa Recursos Genéticos e Biotecnologia, Brasília, Distrito Federal, Brasil. Os ensaios foram realizados na Universidade Estadual de Goiás, Ipameri, Goiás, Brasil. As culturas armazenadas em nitrogênio líquido foram reativadas em batata dextrose ágar (BDA, batata $200 \mathrm{~g} \mathrm{~L}^{-1}$, dextrose 20 $\mathrm{g} \mathrm{L}^{-1}$, ágar $20 \mathrm{~g} \mathrm{~L}^{-1}$ e $\left.\mathrm{pH} 6,5\right)$

\section{Produção de conídios em substrato sólido}

Para a produção de conídios, discos de ágar $(5 \mathrm{~mm})$ foram retirados a partir de colônias de $T$. harzianum com sete dias de crescimento e transferidos para frascos Erlenmeyer de $250 \mathrm{~mL}$ (seis discos por frasco), contendo arroz parboilizado (15 g por frasco), previamente umedecido $\left(60 \% \mathrm{pv}^{-1}\right)$ e autoclavado (121 ${ }^{\circ} \mathrm{C}$ durante $40 \mathrm{~min}$ ). Os frascos foram mantidos no Laboratório de Fitopatologia da Universidade Estadual de Goiás (UEG) a $25{ }^{\circ} \mathrm{C}$ e fotoperíodo de $12 \mathrm{~h}$. Após sete dias, cada frasco teve $10 \mathrm{~g}$ de arroz colonizado recolhido e submetido a uma lavagem com $100 \mathrm{~mL}$ de água 
destilada esterelizada (ADE) e subsequente filtração através de uma gaze estéril. A quantificação dos conídios foi efetuada em câmara de Neubauer. Este ensaio foi realizado em um delineamento inteiramente casualizado, com cinco repetições por isolado.

\section{Colonização de BDA-S por conídios de $T$. harzianum}

Uma quantidade de $10 \mu \mathrm{L}$ de suspensão de conídios obtida conforme o item anterior (previamente ajustada a $10^{4}$ conídios $\mathrm{mL}^{-1}$ ) foi aplicada na superfície de quadrados $(1,5 \times 1,5 \mathrm{~cm})$ de batata dextrose ágarsacarose (BDA-S; batata $200 \mathrm{~g} \mathrm{~L}^{-1}$, dextrose $5,77 \mathrm{~g} \mathrm{~L}^{-1}$, $25 \mathrm{~g}$ de agar $\mathrm{L}^{-1}$, sacarose 7,49 $\mathrm{g} \mathrm{L}^{-1}$ e $\mathrm{pH}$ 6,5). A gota aplicada não foi espalhada sobre a superfície e, portanto, foi esperado um tempo de $10 \mathrm{~min}$ até a sua secagem. Assim, cada quadrado de BDA-S foi cuidadosamente depositado sobre uma lâmina de microscópio e, em seguida, colocado em uma caixa acrílica transparente do tipo Gerbox (11,0 x 11,0 cm). Após, 12, 24, 36 e 48 horas a $25{ }^{\circ} \mathrm{C}$ e fotoperíodo de $12 \mathrm{~h}$, foi estimado o percentual de área dos quadrados de BDA-S colonizado pelas hifas de $T$. harzianum, utilizando imagens obtidas por câmera digital. As imagens obtidas foram ampliadas (3,28 vezes) e impressas para que a medição das áreas colonizadas fosse realizada com uma régua e o percentual de colonização calculado baseando-se na área total do quadrado $\left(\mathrm{A}=1^{2}\right)$. $\mathrm{O}$ percentual de colonização foi integralizado como AACCM (área abaixo da curva de crescimento micelial), por meio da fórmula $\mathrm{AACCM}=\Sigma[((y 1+y 2) / 2) *(t 2-t 1)]$, em que $y 1$ e $y 2$ são duas avaliações consecutivas realizadas nos tempos $t 1$ e $t 2$, respectivamente. $\mathrm{O}$ experimento foi realizado em um delineamento inteiramente casualizado, com cinco Gerbox por tratamento e quatro quadrados de BDA-S por Gerbox.

\section{Análise estatística}

Todos os dados foram submetidos ao teste de Kolmogorov-Smirnov para verificar a normalidade.
Posteriormente, os resultados relativos à produção de conídios em substrato sólido e AACCM foram submetidos à análise de variância e ao teste de ScottKnott $(\mathrm{p} \leq 0,05)$. Os valores referentes ao percentual de colonização de BDA-S (12, 24, 36 e 48h) foram submetidos à análise de regressão. Para as análises, empregou-se o software SISVAR 5.6 (Ferreira, 2011).

\section{Resultados e Discussão}

Quando submetidos à produção de conídios em substrato sólido (arroz parboilizado, umedecido e autoclavado), o resultado mais promissor foi obtido com CEN288 e CEN290, cuja produção foi de $2,6 \times 10^{8}$ e 2,5 x $10^{8} \mathrm{~mL}^{-1}$, respectivamente (Tabela 1 ). Resultados satisfatórios foram também obtidos com os isolados CEN287, CEN289 e CEN316, proporcionando produção de conídios entre $0,5 \times 10^{8}$ e $1,6 \times 10^{8}$ conídios $\mathrm{mL}^{-1}$.

Após 48h da inoculação dos quadrados de BDA-S, foi observado um maior percentual médio da área dos quadrados de BDA-S colonizados pelo isolado CEN289 (87,5\%), em seguida pelo isolado CEN290 (74,6\%) e por último pelos outros isolados, cuja colonização ficou em torno de $50 \%$ (Figura 1). Ao se considerar o progresso da colonização dos quadrados de BDA-S, foi possível obter modelos significativos e com alto coeficiente de determinação para cada isolado, separadamente (Tabela 1). Quanto à AACCM, o isolado CEN289 foi superior aos demais (Tabela 1).

Os grãos de cereais geralmente oferecem vantagens de disponibilidade, custo, rendimento e praticidade para cultivo de bioagentes, sendo, deste modo, os mais utilizados (Thangavelu et al., 2004; Fortes et al., 2007). Teores de umidade elevados no substrato sólido favorecem a produção de conídios do fungo Trichoderma. Isto foi observado quando os níveis de umidade no substrato sólido foram superiores a $60 \%$ (Cavalcante et al., 2008; Milan et al., 2015).

Tabela 1. Produção de conídios em arroz parboilizado. Modelos referentes à colonização de BDA-S (12 a 48h) e área abaixo da curva de crescimento micelial (AACCM) obtida pela colonização superficial de BDA-S mediante aplicação de suspensão de conídios de Trichoderma harzianum (Ipameri, GO, 2018).

\begin{tabular}{lcccc}
\hline Isolados & $\begin{array}{c}\text { Produção de conídios } \\
\left(\text { conídio } \mathrm{mL}^{-1}\right)^{(1)}\end{array}$ & Modelo $^{(2)}$ & $\mathrm{R}^{2}(\%)$ & AACCM $^{(1)}$ \\
\hline CEN287 & $1,6 \times 10^{8} \mathrm{~b}$ & $\mathrm{Y}=0,0627 \mathrm{x}^{2}-2,3390 \mathrm{x}+20,2337$ & 98,41 & $532 \mathrm{~d}$ \\
CEN288 & $2,6 \times 10^{8} \mathrm{a}$ & $\mathrm{Y}=1,3686 \mathrm{x}-22,3950$ & $596 \mathrm{~d}$ \\
CEN289 & $1,4 \times 10^{8} \mathrm{~b}$ & $\mathrm{Y}=0,06547 \mathrm{x}^{2}-1,4079 \mathrm{x}+5,8750$ & 98,98 & $1095 \mathrm{a}$ \\
CEN290 & $2,5 \times 10^{8} \mathrm{a}$ & $\mathrm{Y}=0,05977 \mathrm{x}^{2}-1,4662 \mathrm{x}$ & 98,58 & $929 \mathrm{~b}$ \\
CEN316 & $0,5 \times 10^{8} \mathrm{c}$ & $\mathrm{Y}=1,5223 \mathrm{x}-23,8000$ & 93,73 & $746 \mathrm{c}$ \\
\hline Coeficiente de & $25,29 \%$ & & $12,53 \%$ \\
variação & & & \\
(1) Valores seguidos pela mesma letra minúscula em cada coluna não diferem estatisticamente segundo o teste Scott-Knott (P $\leq 0,05) .{ }^{(2)}$ Todos os modelos foram \\
significativos (P 0,05).
\end{tabular}




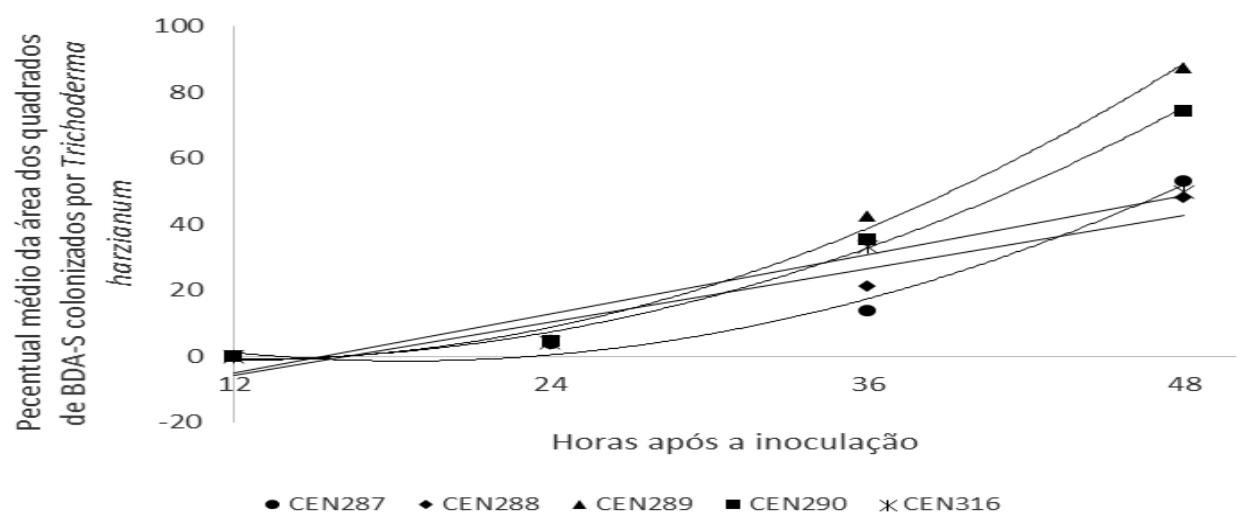

Figura 1. Percentual médio de colonização da área dos quadrados de BDA-S por Trichoderma harzianum às 12, 24, 36 e 48 horas após a inoculação (Ipameri, GO, 2018).

Os resultados monstraram que quando submetidos a teores de umidade superiores a $60 \%$, houve variação quanto à produção de conídios, em que o isolado CEN316 proporcionou os valores mais baixos de produção (Tabela 1). Neste sentido, vale a pena mencionar que a produção de conídios é uma característica altamente intrínseca e dependente do isolado (Carvalho et al., 2008; Milan et al., 2015). Esta característica é especialmente evidenciada quando os isolados são cultivados em arroz ou milho, em que o tempo de imersão em água pode afetar a estrutura sólida e a disponibilidade de nutrientes, tornando a condição de esporulação ótima para cada estirpe diferente, sendo possível diferenciá-las (Cavalcante et al., 2008).

Os isolados empreendidos no controle biológico devem apresentar alta capacidade para colonização de uma superfície sólida (Negri et al., 2010), bem como características genéticas estáveis, baixa exigência em requerimentos nutricionais, habilidade de sobreviver sob condições adversas e eficiência contra uma vasta gama de patógenos em vários hospedeiros.

Quanto à taxa de crescimento micelial, após $48 \mathrm{~h}$ de inoculação dos quadrados de BDA-S, os isolados de $T$. harzianum deste estudo demontraram alto potencial de colonização do meio de cultura, aliados à considerável viabilidade dos conídios produzidos e inoculados nos quadrados em condições controladas, representados pela rápida colonização. Este fato pode ser explicado devido aos isolados apresentarem elevada competição com fitopatógenos no controle efetivo de Fusarium oxysporum f. sp. phaseoli, comprovada nos trabalhos de Carvalho et al. (2014) e Carvalho et al. (2015), além de apresentarem pouca exigência quanto a nutrientes específicos, visto que foram cultivados em meio de cultura rico apenas em sacarose. Assim, os isolados apresentam bom desempenho em requisitos básicos para o emprego em programas de produção massal de controle biológico (Carvalho et al., 2014; Louzada et al., 2016).
O potencial de inibição do crescimento micelial de patógenos pode estar relacionado à competição por recursos disponíveis no substrato. Essa competição pela colonização do espaço e por recursos disponíveis no substrato se traduz na eficiência dos isolados de Trichoderma spp. em mobilizar e assimilar imediatamente os nutrientes à sua volta, o que lhes confere maior rapidez na multiplicação e colonização dos sítios onde se encontram (Benítez et al. 2004). Segundo Carvalho et al. (2014), esse mecanismo contribui para a atividade antagônica, notadamente quando espaço e nutrientes são limitados e, talvez, seja este o principal mecanismo de ação antagonista desses fungos.

A área abaixo da curva de crescimento micelial (AACCM) consiste em uma variável útil na separação de isolados (Lazarotto, et al., 2014). A sobreposição de curvas de progresso do crescimento micelial ou mesmo a proximidade desta pode não permitir a visualização de diferenças entre os isolados, mas a partir da integralização dos percentuais médios de colonização do meio foi possível o cálculo da AACCM, o que permitiu identificar diferenças estatísticas entre os isolados quanto à progressão do crescimento micelial. Ao considerar o progresso de colonização dos quadrados de BDA-S, os modelos de regressão obtidos podem ser comparados entre si e predizer a taxa de colonização do meio sólido por cada isolado antagonista avaliado, o que pode auxiliar estudos futuros que relacionem a AACCM com o potencial de biocontrole.

\section{Conclusões}

Os isolados CEN288 e CEN290 apresentaram bom desempenho para a produção massal de conídios e empreendimento em programas de controle biológico de fitopatógenos.

Os isolados de $T$. harzianum apresentaram capacidade de colonização superficial em meio de cultura rico em sacarose acima de $50 \%$, com $48 \mathrm{~h}$ após a inoculação. 


\section{Agradecimentos}

Os autores agradecem ao Programa de Bolsa de Incentivo à Pesquisa e Produção Científica (PROBIP) da Universidade Estadual de Goiás (UEG), por uma bolsa de produtividade em pesquisa.

\section{Referências Bibliográficas}

Alizadeh, H., Leung, D.W.M., Cole, A.L.J., 2011. Conidiogenic effects of mannose-binding lectins isolated from cotyledons of red kidney bean (Phaseolus vulgaris) on Alternaria alternata. Phytochemistry, 72, 94-99.

Benítez, T., Rincón, A.M., Limón, M.C., Codón, A.C., 2004. Biocontrol mechanisms of Trichoderma strains. International Microbiology, 7, 249-260.

Bhargav, S, Panda, B P, Ali, M., Javed, S., 2008. "Solid-state Fermentation: An Overview". Chemical and Biochemical Engineering Quarterly, 22, 49-70.

Brand, D., Soccol, C. R., Sabu, A., Roussos, S., 2010. Production of fungal biological control agents through solid state fermentation: a case study on Paecilomyces lilacinus against root-knot nematodes. Micologia Aplicada International, 22, 31-48.

Carvalho, D.D.C., Alves, E., Batista, T.R.S., Camargos, R.B., Lopes, E.A.G.L., 2008. Comparison of methodologies for conidia production by Alternaria alternata from citrus. Brazilian Journal of Microbiology, 39, 792-798.

Carvalho, D.D.C., Lobo Junior, M., Martins, I., Inglis, P.W., Mello, S.C.M., 2014. Biological control of Fusarium oxysporum f. sp. phaseoli by Trichoderma harzianum and its use for common bean seed treatment. Tropical Plant Pathology, 39, 384-391.

Cavalcante, R. S., Lima, H.L.S., Pinto, G. A. S., Gava, C. A. T., Rodrigues, S., 2008. Effect of moisture on Trichoderma conidia production on corn and wheat bran by solid state fermentation. Food Bioprocess Technology, 1, 100-104.

Ferreira, D.F., 2011. Sisvar: a computer statistical analysis system. Ciência e Agrotecnologia, 35, 1039-1042.

Fortes, F.O., Silva, A.C.F., Almança, M.A.K., Tedesco, S.B., 2007. Promoção de enraizamento de microestacas de um clone de Eucapyptus sp. por Trichoderma spp. Revista Árvore, 31, 221-228.

Gao, L., Sun, M.H., Liu, X.Z., Che, Y.S., 2007. Effects of carbon concentration and carbon to nitrogen ratio on the growth and sporulation of several biocontrol fungi. Mycological Research, 111, 87-92.

Lazarotto, M., Bovolini, M.P., Muniz, M.F.B., Harakawa, R., Reiniger, L.R.S., Santos, A.F., 2014. Identification and characterization of pathogenic Pestalotiopsis species to pecan tree in Brazil. Pesquisa Agropecuária Brasileira, 49, 440-448.

Lopes, R.B., 2009. Indústria no controle biológico: Produção e comercialização de microrganismos no Brasil, in: Bettiol, W.; Morandi, M.A.B., (Ed.). Biocontrole de doenças de plantas: uso e perspectivas.Embrapa Meio Ambiente, Jaguariúna, pp. $15-28$.

Louzada, G.A.; Barbosa, H.N.; Carvalho, D.D.C.; Martins, I.; Lobo Júnior, M.; Mello, S.C.M., 2016. Relações entre testes com metabólitos e seleção de isolados de Trichoderma spp. antagônicos a Sclerotinia sclerotiorum. Revista Brasileira de Biociências, 14, 9-14.

Machado, D.F.M., Parzianello, F.R., Silva, A.C.F., Antoniolli, Z.I., 2012. Trichoderma no Brasil: o fungo e o bioagente. Revista de Ciências Agrárias, 35, 274-288.

Milan, M.D., Barroso, F.M., Mello, S.C.M., Araújo, M.S., Carvalho, D.D.C., 2015. Regimes de luz na produção de conídios de Trichoderma harzianum para controle do mofo branco em feijoeiro. Pesquisa Agropecuária Tropical, 45, 434439.

Mukherjee, P.K., Latha, J., Hadar, R., Horwitz, B.A., 2003. TmkA, a mitogen-activated protein kinase of Trichoderma virens, is involved in biocontrol properties and repression of conidiation in the dark. Eukaryotic Cell, 2, 446-455.

Negri, G., May De Mio, L.L., Wordell Filho, J.A., 2010. Produção e armazenamento de Trichothecium roseum para uso como biopesticida. Scientia Agraria, 11, 247-254.

Singh, A., Srivastava, S., Singh, H.B., 2007. Effect of substrates on growth and shelf life of Trichoderma harzianum and its use in biocontrol of diseases. Bioresource Technology, $98,470-473$

Spadaro, D., Gullino, M.L., 2005. Improving the efficacy of biocontrol agents against soilborne pathogens. Crop Protection, 24, 601-613.

Thangavelu, R., Palaniswami, A., Velazhahan, R., 2004. Mass production of Trichoderma harzianum for managing fusarium wilt of banana. Agriculture, Ecosystems \& Environment, 103, 259-263.

Wood, R.K.S., Tveit, M., 1955. Control of plant diseases by use of antagonistic organisms. Botanical Review, 21, 441-492. 